\title{
Using Field Methods as an Instructional Tool
}

\section{Donald H. Wulff \& Jody D. Nyquist}

University of Washington

As instructional development specialists, we are frequently called upon to assist in course design and to recommend a variety of teaching strategies that instructors can use to achieve course objectives. Although most of us can readily suggest ways to work with methods such as lectures, textbooks, discussions, audio-visual materials and demonstrations, we tend to overlook less familiar instructional tools that can be incorporated into the design of courses. One such instructional tool that has not received adequate attention as a potential teaching strategy is the use of field methods that enable undergraduates to function as researchers while learning the content of a course.

Traditionally, field study methodology has been used by such science disciplines as archaeology, biology, marine biology, forestry, geology, and others to enable students to observe, analyze, classify, and report naturally occurring events in the environment. These long-term studies, not to be confused with the occasional "field trip," provide students with a rigorous experience in systematically applying a researcher's tools and/or practices to an object of study, whether it be taking part in archacological digs, charting whale migrations from an oceanography vessel, or assessing the devastation caused by gypsy moths. In each case, undergraduates profit from discovering for themselves, through hands-on experience, the meaning of concepts explicated in a particular course. Although field-based learning is often expensive because of the logistics involved, professors and students alike testify to the power of such learning processes.

From To Improve the Academy: Resources for Student, Faculty, and Institutional Development, Vol. 7. Edited by J. Kurfiss, L. Hilsen, S. Kahn, M.D. Sorcinelli, and R. Tiberius. POD/New Forums Press, 1988. 
In disciplines other than the sciences, similar field study methods have been used to observe, analyze, classify and report human behavior occurring in natural environments. Typically, such methods are presented in graduate level, primarily qualitative research methodology courses, in disciplines including anthropology, business, sociology, psychology, education, speech communication, social work, architecture, and others. These field study methods, however, can be and have been successfully incorporated into undergraduate classrooms as instructional strategies designed to involve students in mastering course content in various disciplines.

\section{Defining Field Methods as an Instructional Tool}

As the name suggests, field methods are used in situ, in the actual setting in which a particular phenomenon of interest occurs. Philipsen (1982) suggests that the investigator who uses such methods "deliberately spends as much time as possible in the theater of observation" and "becomes personally involved with, or at least exposed to, the phenomena of interest" (p. 9). Although field researchers can use a variety of techniques to collect data, common field methods include observing, interviewing, and collecting documents in a specific environment.

The use of field methods as an instructional strategy, then, entails getting students into a setting where they can collect information about a particular component of the course curriculum by observing, interviewing, and/or examining written materials. Some variation of the method is used whenever we ask students to observe or conduct interviews outside a classroom. However, when we think of the use of field methods as a learning tool as well as a research tool, we think of the student as a researcher who will learn in a setting outside the classroom, while simultaneously using the information garnered to contribute to the development of the course content in the classroom setting.

Field methods are particularly potent in courses where students can observe human processes or interactions. For example, a psychology instructor who wants students to be able to identify sources of positive and negative influence on the development of self-concept may ask students to conduct interviews or observe children in a variety of contexts. An education instructor who wants future teachers to be able to describe how lessons plans are implemented in the classroom may ask students to observe and/or interview teachers. Finally, an instructor who wants students in an organizational communication class to be able to explain the 
dynamics of superior/subordinate relationships may want students to observe superior/subordinate relationships in an organization.

Although field methods might be incorporated in such courses in a variety of ways, it is sometimes difficult to imagine how a course that uses such methods might be structured. The following case, then, illustrates the use of field methods as a way of achieving important course objectives in a course taught by one of the authors of this article.

\section{Using Field Methods in a Speech Communication Course}

The use of field methods as an instructional tool is a strategy central to a speech communication course entitled "Communication in Children's Environments." The course, designed primarily for juniors and seniors who intend to work closely with children, focuses primarily on the development of communication in children 5-12 years of age. The general goal of the course is to help students understand how communication abilities develop in children and how communication competence in children can be facilitated.

As the instructor began to plan her course to accomplish the general goal, she identified the specific outcomes she wanted her students to achieve during the course. As a result of her course, she wanted students to be able to:

1. Describe what "kid society" is like;

2. Identify the reasons why children communicate in various contexts;

3. Identify communication competencies needed by children in a variety of contexts;

4. Explain cognitive and communication development and a functional perspective of communication competence;

5. Compare and contrast a functional perspective of communication competence with the reality of "kid society";

6. Explain how to foster development of functional communication competence in children;

7. Describe ways to assess children's communication competence.

In addition to identifying these very specific objectives for her course, the instructor also outlined some more global educational goals she hoped to accomplish through the design of her course. She hoped to make the course intellectually stimulating by involving the students in their own learning, by encouraging them to think about and challenge the content of the course, and by providing activities to assist them in developing and supporting their own conclusions. 
With these objectives and goals in mind, the instructor began to determine appropriate instructional methods to assist students in mastering the content. Although she initially felt that much of the information could be relayed simply through reading, lecture and discussion, she wanted to involve the students more directly in determining what "kid society" is like and what skills children need in order to communicate competently. In order to enable students to describe for themselves the society, the reasons why children communicate and the competencies needed, the instructor decided to have students observe in various contexts where children are communicating. Thus, to provide the information necessary for students to achieve the first three specific objectives of the course, the instructor incorporated data gathered in the form of students' field notes. In addition to providing "hands on" learning, then, this approach also cmpowered students to assist in creating content for the course.

Once the instructor made the decision to use ficld methods to accomplish the first three course objectives, she planned how to use other instructional methods in the course. She reasoned that although information that students generated in the field would be an important part of the course, it could not provide all the information necessary to achieve the course objectives. She, therefore, decided to use the textbook and lecturediscussion methods to provide students with essential information about children's cognitive and communication development and about the functional perspective of communication competence. This information also provided frameworks for the field studies. Through these methods, she reasoned, students would be able to accomplish the fourth major objective of being able to explain cognitive and communicative development and a functional perspective of communication competence.

Finally, the instructor decided to use interactive methods to enable students to compare and contrast the results of their observations with the frameworks presented in readings and lectures and to develop their own perspectives. She planned to have students present their own tentative hypotheses and conclusions in class and small group discussions. An important part of that process would be synthesizing the field data and comparing and contrasting it with the information presented in the text and lectures. In an effort to get students to balance their thinking with ideas generated in the course, the instructor decided to require students to work in groups to produce a paper that explained how communication competence should be fostered and assessed. Thus, the total course design included lecture, teacher-led discussions, small group activities, and written assignments, with a strong emphasis on field study.

To enable students to perform as researchers, the instructor arranged to dedicate class time at the beginning of the quarter to a presentation by 
a researcher experienced in field methods. The researcher explained to the students what it means to enter a natural setting in response to a question and collect, classify and report data systematically. Part of the presentation focused on taking field notes, including what to record, how to separate observations and inferences, and how to formulate tentative hypotheses. In addition, the researcher showed students how to analyze information from field notes by classifying it into categories and looking for themes within the categorized data. Finally, the researcher explained how students could present the results of their observations and support their findings with specific evidence from their field notes.

To allow students to fulfill the field study component of the class, the instructor released students for one hour each week to observe elementary-age students in a variety of settings ranging from informal environments such as ice cream shops, swim team turnouts, Brownie and Boy Scout troop meetings, and various organized sports programs held at community centers to the more structured Sunday School and elementary classroom environments. The following set of questions guided students in their collection of data:

1. How would you describe the "kid society"?

2. For what purposes do children communicate?

3. How do the children you are observing reflect what experts say are ageappropriate communication behaviors?

4. What are some instances in which children are informing others?

5. What are some instances in which children are expressing their feelings to their peers, siblings, other children or adults?

6. What are some instances in which children are persuading others?

7. What are some instances in which children are using imaginative or ritualized communication behavior?

8. What are some instances in which you believe adults are communicating effectively with children? What is happening? What are the implications?

At the beginning of each week, students brought their previous week's field notes to class and participated in a synthesizing teacher-led discussion covering the assigned question. Often student contributors displayed a large set of qualitative data on the board and analyzed it collectively in an effort to find themes and patterns which would provide insights into children's communication development and competence. During this process the students generated tentative hypotheses and tested them against "expert explanation" derived from the textbook and lecture materials of the course, the data represented in the day's discussion, and their own additional data collection experience. The discussions, which were always lively, were based on rich data collected on real children 
operating in natural environments; they included a comparison of expert knowledge and student-generated observations as the instructor intended. Week by week students grew more confident in their ability to observe, analyze, classify and report data and to challenge textbook author and course instructor opinions and conclusions. In actuality; the class became a giant research team of twenty-five members collaborating to find insights into the development of communication competence in children.

In both the midterm exam and the final paper the instructor asked students to express their conclusions about children's communication development and competence derived from the field study discussion. Thus, the field study method employed in the class helped generate the course curriculum.

\section{Advantages of Using Field Methods as an Instructional Strategy}

In addition to helping the instructor achieve the most immediate course objectives, the use of field methods as a teaching-learning strategy also allowed the instructor to achieve some of the more general educational goals. First, the use of field methods provided motivation for the students to get more directly involved in their own learning. In its 1984 Report, the Study Group on the Conditions of Excellence in American Higher Education recommended that one of the three critical conditions of excellence was student involvement and that "Faculty should make greater use of active modes of teaching and require that students take greater responsibility for their learning" (p. 27). These sentiments have been echoed by practitioners who have in their classrooms successfully incorporated methods that eliminate student passivity (Kraft, 1985; Phoenix, 1987). Furthermore, Meyers (1986) suggests that to develop motivation, "students must actively struggle with real problems and issues" (pp. 8-9). The use of field methods in the communication course actually allowed students to be engaged in the real issues of developing communication competence in children. Instead of being passive receptacles for knowledge dispensed in the classroom, the students were researchers involved not only in the field where they collected data, but also in the classroom where they sorted, classified, and synthesized information they obtained in the field. They learned to compare and contrast the content from the field with that they were exposed to through textbook authors and instructor explanations in the classroom. In many instances, the learning was a collaborative process in which students worked 
together to understand communication competence in children more fully.

A second advantage was that the instructor got the students to think critically about communication competence in children. In his book on teaching students to think critically, Meyers (1986) suggests that instructors should provide opportunities for students to practice critical thinking skills and attitudes in specific disciplines; in the case of the communication course students had opportunities to think like communication scholars who want to foster communication competence in children. As students gathered data from the field, analyzed it, and brought their tentative hypotheses to class each week, they were able to interpret their findings in terms of frameworks presented in class and to ask questions and seek answers to the larger question of how one fosters and assesses communication competence in children. Also, using basic field methods provided students with a way of thinking about the research process in the discipline of speech communication, including collecting and analyzing data, testing and validating hypotheses, and presenting results.

A third advantage that the instructor obtained in using field methods was increased consistency between what was discussed in the classroom and what happens in the real world. In the 1987 American Educational Research Association Presidential Address arguing that schooling is becoming isolated from what exists in the world outside the school, Resnick (1987) contends that school learning often focuses on symbols detached from their referents in "any meaningful context" (p. 15). As a result, students frequently study information that does not generalize to the world outside the classroom. In the communication course, students may have read the textbook, listened to the instructor, or even tried to cite examples that they could remember from their own childhood experiences; yet, the $\mathrm{i}$-formation may not have been representative of the issues and problems of the real world. However, when these students collected data in natural settings, they obtained a much richer sense of the phenomena; and through their discussions of their findings in class, they could be more confident that their decisions regarding fostering and assessing communication competence would translate to the actual needs of the "kid society." In the communication course, then, learning was enhanced, as Drake (1983) suggests, by "stressing relationships between classrooms and the world 'out there"' (p. 271).

Although the use of field methods allowed the communication instructor to achieve these general educational goals as well as her specific course objectives, she did not incorporate such methods without careful consideration of the role they would play in the overall course design. Be- 
cause the use of field methods as a learning-teaching tool is an atypical instructional strategy, instructors need to plan carefully for the use of such methods. In some cases, extensive use of field methods as a teaching tool in a specific course may require restructuring the entire course with great variation from more traditional methods that center on the teacher or the textbook. Minimally, use of the methods requires training students in field study research methods. The following discussion, then, identifies some of the major guidelines to be considered in assisting instructors in their use of field methods as an instructional tool.

\section{Guidelines}

\section{Objectives}

It is important to have instructors, first of all, identify the major learning outcomes desired for a course and then determine if students will benefit sufficiently from the time spent in traveling to the field, collecting data, and conducting analyses. If a major objective of a course is to have students master a body of content that has already been clearly defined by the instructor or a textbook, then field methods may not be appropriate. If, however, major goals for a course include having students compare and contrast information from different sources or learn to analyze, synthesize and categorize, then instructors might be encouraged to consider ways that field methods could be incorporated into their classrooms. It is also important to have instructors consider the benefits that can be derived from the use of field methods in terms of increased student interest and motivation, content relevance, and development of critical thinking skills.

\section{Course Content}

Although field methods can be useful for contributing content that can enrich a course and make it more interesting for students, such methods probably cannot provide the only source of information for an undergraduate course. If students are to learn to think as researchers who gather data to answer their questions and solve their problems, they must also learn to interpret that data in terms of previous information, especially research and theory, that has focused on the phenomena of interest. Meyers (1986) points out that, especially for critical thinking to take place, "a teacher must present some explicit perspective or framework for disciplinary analysis - a structure for making sense of the materials, issues, and methodologies of the discipline being taught" (p.6). This kind of con- 
tent must be presented, then, either through the textbook or through the information that the instructor provides for the course.

\section{Other Instructional Strategies}

Although field methods can accomplish a variety of instructional objectives, they cannot, by themselves, provide the only tools for mastering course content. They will probably have to be integrated with reading assignments, lectures, and interactive modes such as teacher-led and smallgroup discussion. Particularly when such methods are being used to accomplish critical thinking objectives, they require that students have ample opportunity to summarize, test, express and support their conclusions. Thus, most often, such methods also have to be complemented with oral and written interactive modes.

\section{Logistics}

The biggest logistical problem in using field methods as a way of helping students learn is one of matching students with appropriate field settings. Depending on the level of a college group, an instructor may be able to make the assignments and let students decide on their own about issues of entry and access. However, if students need assistance finding and arranging to visit appropriate field sites, the process can be challenging, particularly if the instructor is new to the area or teaching the course for the first time. Additionally, once students have been matched with appropriate settings, they still need information on policies and guidelines for obtaining permission to conduct studies in particular field settings. Traveling to and from a field site, observing, and interviewing also take time. Consequently, instructors should be cautioned to balance the amount of class time they require of students with the perceived value of the exercise. They may even want to structure their course so that students are given some portion of the regularly scheduled class time each week to work in the field as students were in the case study.

\section{Methodology}

Many undergrảduates will not have been exposed to field methods. Even though some students may have conducted interviews or more formal observations, most students will not have treated such methods as systematic ways of collecting and analyzing data and reaching conclusions. Therefore, instructors will want to schedule time at the beginning of the course or before a specific exercise to talk very basically to the students 
about such topics as determining a research question, gaining access to the field as a participant or nonparticipant observer, taking field notes during interviews and observations, collecting documents, moving from field notes to tentative hypotheses, analyzing the data, and reporting the results of their work. As they prepare students, however, instructors may also want to enlist the services of a guest speaker, perhaps someone else in the department, who specializes in such methodology. At the end of this article is a list of additional sources that describe approaches to field methods.

Regardless of who provides the background about the use of field methods, for undergraduates, it must be presented at the most basic and concrete levels. Since it does take time to prepare students and get them organized for the logistics of field study, instructors should be encouraged to consider carefully whether they want to use field methods as an instructional tool for one or two projects during their courses or as an ongoing learning process throughout the term. Typically, undergraduate competence in research methodology need not match that of graduate student levels, since the aim is to provide an active learning process - not to publish a research report. Students do need, however, the basic tools that will permit them to gather their data systematically and analyze it to the extent that they can discuss with the instructor and other students those representations of data that appear to contradict theory or expected outcomes.

\section{Student Roles}

For the most part, students will have had very little experience in the researcher role. Furthermore, they may typically come to a class expecting the instructor to be the major source of information for the subject. Consequently, instructors will need to spend time discussing with students not only the appropriate protocol for getting into and working in the field as researchers, but also developing ideas and contributing to class as a result of their research. Students may need to understand that a major part of the content for a particular assignment or course is based on the data they generate in the field and that much of the comparison, contrast, and discussion in the class will rely on tentative hypotheses and conclusions that they generate from their analyses of field notes.

\section{Teacher Role}

When instructors use field methods as an instructional method, they should be prepared to assume a variety of roles, including content expert, 
field methods practitioner, individual consultant, and facilitator. As content expert, the instructor will be responsible for providing the content to which students may compare and contrast the data they generate in the field. In the role of field methods practitioner, instructors may have to assist students in deciding how to obtain data in a particular context or how to categorize and synthesize their data as a class. Instructors may assume a consultant role as they work with individual students who have particular problems analyzing their data or who have generated particularly interesting or puzzling insights about the phenomenon being studied. Finally, as facilitators, instructors will have to provide ongoing summary, analysis and synthesis to help the students tie the information generated in the field to the important instructional objectives of the course.

\section{Summary}

Although the use of field methods as an instructional tool may require major rethinking and restructuring of the traditional ways that some courses have been taught, the value of such methods cannot be disputed. Field methods provide one of the few instructional tools that can help faculty achieve their specific course goals as well as involve students, increase their interest, get them to think critically, and make sure their learning is relevant to what actually happens in the real world. As faculty developers we can play important roles not only in helping faculty recognize the possibilities of such methods, but also in helping them address the special considerations for incorporating such methods in their teaching.

\section{References}

Drake, H. L. (1983). Classroom assignments minus the rearview mirror. Communication Quarterly, 31, 271-173.

Involvement in learning: Realizing the potential of American higher education. (1984). Study Group on the Conditions of Excellence in American higher Education. National Institute of Education, U. S. Department of Education, Washington, D. C.

Kraft, R. G. (1985). Group-inquiry turns passive students active. College Teaching, 33, 149-154.

Meyers, C. M. (1986). Teaching students to think critically. San Francisco, CA: Jossey-Bass. 
Philipsen, G. (1982). The qualitative case study as a strategy in communication inquiry. The Communicator, 12, 4-17.

Phoenix, C. Y. (1987). Get them involved: Styles of high-and low-rated teachers. College Teaching, 35(1), 13-15.

Resnick, L. B. (1987). The 1987 presidential address: Learning in school and out. Educational Researcher, 16, 13-20.

\section{Additional Sources on Field Methods}

Dobbert, M. L. (1982). Ethnographic research: Theory and application for modern schools and societies. New York: Praeger Publishers.

Fielding, N. G., \& Fielding, J. L. (1986). Linking data. Sage University paper series on Qualitative Research Methods (Vol.4). Beverly Hills, CA: Sage Publications.

Goetz, J. P. , \& LeCompte, M D. (1984). Ethnography and qualitative design in educational research. Orlando, FL: Academic Press.

Kirk, J., \& Miller, M. L. (1986). Reliability and validity in qualitative research. Sage University paper series on Qualitative Research Methods (Vol. 1). Beverly Hills, CA: Sage Publications.

Lincoln, Y. S., \& Guba, E. G. (1985). Naturalistic inquiry. Beverly Hills, CA: Sage Publications.

Miles, M. B., \& Huberman, J. A. (1984). Qualitative data analysis. Beverly Hills, CA: Sage Publications.

Patton, M. Q. (1980). Qualitative evaluation methods. Beverly Hills, CA: Sage Publications. 